$\begin{array}{ll} & \text { Etnográfica } \\ \text { etnográfica } & \text { Revista do Centro em Rede de Investigação em }\end{array}$

Antropologia

vol. 25 (3) | 2021

Vol. 25 (3)

\title{
El género como catástrofe: performatividades religiosas y la emergencia de la "ideología de género" en Brasil
}

The gender as catastrophe: religious performativities and the emergence of the "gender ideology" in Brazil

\section{Flávia Melo}

\section{(2) OpenEdition}

\section{Journals}

Edición electrónica

URL: https://journals.openedition.org/etnografica/10190

DOI: $10.4000 /$ etnografica. 10190

ISSN: 2182-2891

\section{Editor}

Centro em Rede de Investigação em Antropologia

Edición impresa

Fecha de publicación: 1 octubre 2021

Paginación: 795-816

ISSN: 0873-6561

Referencia electrónica

Flávia Melo, «El género como catástrofe: performatividades religiosas y la emergencia de la "ideología de género" en Brasil», Etnográfica [En línea], vol. 25 (3) | 2021, Publicado el 28 octubre 2021,

consultado el 08 enero 2022. URL: http://journals.openedition.org/etnografica/10190 ; DOI: https:// doi.org/10.4000/etnografica.10190

\section{(c) (7) (8)}

Etnográfica is licensed under a Creative Commons Attribution-NonCommercial 4.0 International License. 


\section{El género como catástrofe: performatividades religiosas y la emergencia de la "ideología de género" en Brasil}

\section{Flávia Melo}

Desde finales de la década de 1990 ha venido proliferando una literatura religiosa que utiliza la expresión "ideología de género" para denunciar una grave amenaza, capaz de liquidar la existencia humana. En el transcurso de la última década, la expresión ha sido progresivamente incorporada por diferentes grupos políticos y ha conquistado un espacio muy significativo de decisiones sobre el reconocimiento de derechos sexuales y reproductivos, políticas educativas, procesos de paz y elecciones en muchos países del mundo. En este artículo recurro a la teoría de la performatividad de Judith Butler para analizar las discursividades manejadas en la producción de esa categoría, su contexto de emergencia y los efectos de su difusión en Brasil.

PALABRAS CLAVE: estudios de género, derechos sexuales y reproductivos, parlamento brasileño, ideología de género, escatología

The gender as catastrophe: religious performativities and the emergence of the "gender ideology" in Brazil - Since the late 1990's, a religious literature that uses the term "gender ideology" to denounce a serious threat, capable of liquidating human existence has proliferated. Over the last decade, the expression has gradually been incorporated by different political groups and has gained a significant place in decisions regarding the recognition of sexual and reproductive rights, educational policies, peace processes and electoral disputes in many countries. In this article, I resort of Judith Butler's theory of performativity to analyze the discursiveness engendered in the production of this category, its emergency context and the effects of its diffusion in Brazil.

KEYWORDS: gender studies, sexual and reproductive rights, Brazilian parliament, gender ideology, eschatology

MELO, Flávia (flaviamelo@ufam.edu.br) - Universidad Federal del Amazonas, Brasil 


\section{EN NOMBRE DE DIOS Y DE LA FAMILIA}

"Señor presidente, señoras y señores diputados, nación brasileña que nos asiste en este momento. El PHS es un partido que demuestra plenamente su democracia. Cuando entré en el PHS saliendo del PROS, tenía, evidentemente, mis convicciones. El partido, por unanimidad, asumió una posición intransigente contra el aborto, contra la eutanasia, contra el infanticidio y contra la ideología de género. Hay consenso entre el partido y los diputados cuando se trata de temas importantes para nosotros que somos cristianos. Aunque el partido también ha indicado que, en determinadas situaciones, liberaba a su bancada para tomar la postura que decidiese, cuando no fueran cuestiones que traíamos del compromiso con las bases, las cuestiones humanitarias. El Partido Humanista de la Solidaridad tiene sus cuestiones programáticas, pero en este momento que vive Brasil y donde decidimos si una presidenta se queda o sale, el partido reunió a su ejecutiva y a todos sus diputados. Somos siete diputados federales y el partido tomó una decisión: el partido votará a favor del impeachment (subrayado mío)." I

En la mañana del 15 de abril de 2016, tuvo inicio una de las más largas sesiones de la Cámara de Diputados de Brasil con el objeto de votar la apertura del proceso de destitución de la presidenta de Brasil, Dilma Rousseff, del Partido de los Trabajadores (PT). Durante varias horas consecutivas y a lo largo de tres días, cientos de parlamentarios y parlamentarias expresaron las razones de su voto a favor o en contra la destitución de la presidenta. Finalmente, "en el nombre de Dios y de sus familias", la mayoría del parlamento votó por el sí (Prandi y Carneiro 2018).

El Partido Humanista de la Solidaridad (PHS), representado por su líder, el diputado Givaldo Carimbão, ${ }^{2}$ se declaró contra el aborto, la "ideología de género", la eutanasia y a favor del proceso de destitución de la presidenta. En 2015, el mismo congresista integró la Comisión de Educación de la Cámara Federal y actuó de manera decisiva para la exclusión de la perspectiva de género en los planes de educación de los estados y municipios brasileños.

La declaración del PHS, por otra parte muy representativa, expuso la relevancia de las cuestiones de género y sexualidad en los debates políticos contemporáneos en Brasil, principalmente en el poder legislativo. No por casualidad, los temas rechazados por el partido coincidían con parte importante de la agenda de los derechos sexuales y reproductivos presentes en la historia de las

l Disponible en < https://youtu.be/kI5QgVU35I4 > (última consultación en octubre 2021).

2 Disponible en < http://www.fgv.br/cpdoc/acervo/dicionarios/verbete-biografico/carimbao-givaldo > (última consultación en octubre 2021). 
propuestas legislativas en Brasil desde la apertura democrática (Natividade et al. 2009).

Sin embargo, a pesar de que la confrontación en torno a estos temas esté presente en la historia del legislativo brasileño, al menos desde hace 40 años (Natividade et al. 2009), el uso de la expresión "ideología de género" en la Cámara de Diputados es muy reciente. La notoriedad le llega en 2014 con la aprobación del Plan Nacional de Educación (PNE) y desde entonces ha sido subrayada en decenas de acciones parlamentarias vinculadas a grupos político-religiosos en todo el país. Tal y como sucedió en el proceso de impeachment, el término volvió a resurgir con mucha más fuerza en las elecciones presidenciales del año 2018 y fue una importante herramienta para la victoria del candidato de retórica de extrema derecha Jair Messias Bolsonaro (Partido Social Liberal - PSL).

En vista de la manera cómo la expresión "ideología de género" conquistó una posición significativa en la vida política brasileña - y sumándome al creciente número de trabajos dedicados a comprender ese fenómeno en Brasil y otros países - este artículo busca señalar cómo las cuestiones de género y sexualidad han adquirido notoriedad en la contemporaneidad brasileña, así como demostrar los contextos de emergencia de una categoría que distorsiona el concepto de género, propaga el pánico moral (Rubin 1993; Miskolci y Campana 2017; Rondón 2017; Borges y Borges 2018; Balieiro 2018), posee un contenido escatológico poderoso, y ha ejercido una gran influencia en acontecimientos recientes muy relevantes de la vida política en Brasil, tales como la aprobación del PNE en el año de 2014, el impeachment de la presidenta Dilma Rousseff en 2016 y las elecciones presidenciales de 2018. Además de estos aspectos, los fenómenos aquí descritos demuestran la correcta proposición de Vaggione (2010) sobre la centralidad de la religión en la comprensión de las políticas contemporáneas.

Me centraré en el caso brasileño, si bien es cierto que hechos similares son observables en otros países como Italia y Francia (Garbagnoli 2014), Colombia (Vigoya y Rondón 2017), Perú (Biroli 2019), México (López 2018), España (Cornejo-Valle y Pichardo 2017) y muchos otros (Paternotte y Kuhar 2018); además del actual reconocimiento de estos como transnacionales (Cornejo--Valle y Pichardo 2017; Corrêa 2018). Sin embargo, mi análisis pretende ir más allá de los límites nacionales y unirse a otros intentos de entender estos fenómenos y, quizá, plantear nuevas maneras de conducirnos en este campo.

En cuanto a la importancia del caso brasileño, cabe explicar que la campaña antigénero coincide con un proceso de transición poblacional de mayoría católica a mayoría evangélica, estimada por los demógrafos para 2022. En cierta medida, la acción evangélica en esos procesos políticos muestra cómo el evangelismo no solo puede suplantar al catolicismo como la mayor fe nacional, 
pero, máximamente, ha transformado la relación entre la Iglesia y el Estado. Además del debate sobre la secularización, estos procesos inciden en el papel geopolítico del país en América Latina y, sobre todo, en su posición en el consejo de derechos humanos de la ONU.

El punto de partida de mi estudio es el proceso de aprobación del PNE, momento en el que surgió en Brasil la cruzada contra el género. Acompaño su desarrollo y sus efectos hasta las elecciones presidenciales de 2018. La descripción no sigue la cronología de los hechos, sino el movimiento de actores y discursividades, aparentemente desconectados, y su articulación con los acontecimientos que tuvieron lugar en el campo de los derechos sexuales y reproductivos, así como por la defensa de la equidad de género en la educación brasileña.

Para analizar las discursividades manejadas en la formación de la categoría "ideología de género", así como su contexto de emergencia y los efectos de su difusión en Brasil, recurro al concepto de performatividad de Judith Butler (2002, 2018), entendido como una modalidad específica de poder forjada en actos enunciativos que reiteran normas y producen lo que declaran a través de prácticas regulares y sancionadas (Butler 2002). De acuerdo con este entendimiento, el acto mismo de enunciación de la "ideología de género" le otorga materialidad a través de su reiteración regular y repetición de normatividades de género legitimadas por una moral religiosa autoritaria.

Tras una retrospectiva de la trayectoria reciente del término "ideología de género" en la vida política brasileña, presento una genealogía basada en publicaciones cristianas ampliamente difundidas en las redes sociales como las principales fuentes y orígenes del uso de esa expresión. Si bien mi esfuerzo genealógico no sea original, intento sumarme a otros trabajos dedicados a comprender el antagonismo al género (Miskolci y Campana 2017; Junqueira 2017; Corrêa 2018). Así, en la tercera parte, enumero tres cambios semánticos que añadirán nuevos sentidos al género y que buscan estigmatizarlo bajo el término "ideología de género".

Em cuanto, a la cuarta parte, trataré de demostrar cómo el poder legislativo se ha configurado en un importante espacio de coalición política y, así, describo la consolidación de la cruzada contra el género en Brasil. Finalmente, expongo una síntesis de las principales estrategias observadas en las performatividades religiosas, con particular atención a su dimensión escatológica.

\section{iHÁGASE LA LUZ! LA GÉNESIS DE LA “IDEOLOGÍA DE GÉNERO”}

A lo largo de los últimos 50 años, el término "género" fue empleado para cuestionar la naturalización de los roles sexuales y adoptado, por primera vez, por el psicoanalista Robert Stoller (1964) para diferenciar el sexo de la identidad. Así, el autor definió el carácter cultural de la identidad, denominándola 
"identidad de género". Años más tarde, la antropóloga Gayle Rubin (1975) propuso el "sistema sexo/género", descrito como modos de intervención social sobre el sexo humano basados en el control de la sexualidad femenina, en el tabú del incesto y en la heterosexualidad. A mediados de la década de 1980, la historiadora Joan Scott (1995) definió "género" como una categoría relacional de análisis histórico, postulando que la experiencia corporal debería ser comprendida como insertada en procesos sociales e históricos. En la década siguiente, la filósofa Judith Butler (1990) formuló el concepto de "performatividad de género", según el cual todos los cuerpos son productos de discursividades reguladoras. No obstante, al mismo tiempo que tales teorizaciones eran formuladas, el género también se constituyó como una importante herramienta política forjada por los movimientos de mujeres, feministas y LGBT para reivindicar reconocimiento, derechos, proponer políticas públicas e intervenir en las relaciones sociales.

Asimismo, la "ideología de género" es oriunda del campo religioso, siendo difundida por intelectuales y teólogos católicos (Ratzinger 1997; O’Leary 1997; Revoredo 1998; Scala 2010; Guisasola 2018) y creada en finales de los años 1990 (Revoredo 1998). Ciertos autores la consideran un "dispositivo retórico efectivo" (Garbagnoli 2014: 25 1), para otros es una "categoría política reaccionaria" (Junqueira 2017: 25), una "distorsión semántica” (Cornejo-Valle y Pichardo 2017: 66) o una "categoría acusatoria" (Luna 2017: 34). Aunque sus orígenes se remontan a finales del siglo XX, el activismo contrario al género logró más fuerza y visibilidad, tan sólo 20 años después, yendo mucho más allá de las iglesias y sus líderes.

Una breve búsqueda en la web demuestra lo difícil que es aclarar los orígenes de este término. En 2016, la búsqueda con la expresión exacta - solamente en lengua portuguesa - indicaba alrededor de 500 mil resultados. En diciembre de 2018, esa misma búsqueda generó más de un millón de resultados. Actualmente, la página de búsquedas de Google ofrece una definición generada a partir de los datos compartidos en la web: "Expresión utilizada por los críticos de la idea de que los géneros son, en realidad, construcciones sociales. Para los defensores de esta 'ideología', no existe sólo el género 'masculino' y 'femenino', sino un espectro que puede ser libremente escogido por el individuo".

Para cumplir con mi intento de investigar su génesis, seleccioné a los autores y autoras, así como los libros más citados frecuentemente en las fuentes consultadas en las redes sociales, y elegí de entre ellos las publicaciones más remotas. Hasta el momento, el análisis de estos datos sugiere la existencia de dos líneas discursivas: una línea vinculada a la tradición católica, con una extraordinaria elaboración bibliográfica, y otra de tradición evangélica, cuya actuación en Brasil se ha concentrado en el parlamento, en el "televangelismo" (Francisco 2011) y en las redes sociales. 
En la línea discursiva católica, el libro de Dale O’Leary, The Gender Agenda (1997), es la más antigua y la principal referencia a la alusión de una ideología introducida por la "perspectiva feminista de género". En el libro, la autora analizó las conclusiones de la IV Conferencia Mundial de Mujeres (1995, Pequín) para demostrar cómo el término género - y una agenda política - fue progresivamente inducido por agencias internacionales, gracias a la actuación de activistas y feministas "radicales". Para O'Leary, la perspectiva de las mujeres habría sido suplantada por la perspectiva de género. El "feminismo de género", surgido en la década de 1970 bajo influencia de las teorías de clase, sería un "movimiento radical y neomarxista de rechazo a la familia, a la maternidad y de apoyo a la promiscuidad" (O’Leary 1997).

La reacción religiosa a la introducción del concepto de género es atentamente analizada por Corrêa (2018), que se dedicó al análisis del repudio transnacional al género en las Naciones Unidas. Rememorando el proceso de preparación de la conferencia de Pequín, la autora recuerda presenciar:

“a un delegado de Sudán exigir vigorosamente el 'corcheteamiento' de la palabra [género] y ser apoyado por otros países islámicos, sin que la coordinadora de la sesión pudiera contener su largo y agresivo discurso. En esa escena, las manos ni tan invisibles del Vaticano eran detectables, pues, aunque la Santa Sede no se ha manifestado, las delegaciones de Honduras, Nicaragua y El Salvador, sus aliados fieles, apoyaron la posición sudanesa." (Corrêa 2018: 3)

En efecto, la publicación del libro de O’Leary fue una más de las expresiones del repudio religioso al avance de la perspectiva de género en las decisiones y orientaciones de las Naciones Unidas. Sin embargo, en los años siguientes a Pequín, verificamos la gradual inclusión de la perspectiva de género, no sin resistencias, a través de directrices para la equidad entre hombres y mujeres, leyes contra la violencia de género, el reconocimiento jurídico del feminicidio y el monitoreo del avance de los derechos de las mujeres y de LGBT en los países miembros.

Poco tiempo después de The Gender Agenda, fue publicado por la Conferencia Episcopal Peruana el documento La Ideología de Género: Sus Peligros y Alcances (1998). Por primera vez, el obispo Oscar Alzamora Revoredo utiliza la expresión “ideología de género” y, basándose en el libro de O’Leary, insta a los católicos a posicionarse contra su avance. Ese mismo texto fue publicado por el Consejo Pontificio para la Familia de Madrid/España (Revoredo 2004 [1988]: 593-608). Con referencias al pensamiento de Judith Butler, cuyo trabajo califica como "un cuento de ciencia ficción" (Revoredo 1998: 2), el documento presenta definiciones procedentes de los Estudios de Género y Sexualidad y denuncia la "agenda" de los derechos sexuales y reproductivos introducida en los países "en desarrollo": 
"La ideología de género es un sistema cerrado, con el cual no hay modo de razonar. Existen muchas personas que no están todavía al corriente de los peligros de esta nueva propuesta. Considerando la posición central que esta perspectiva ha logrado tomar en la cultura norteamericana, se trata de un reto que debe ser afrontado con vigor para evitar las graves consecuencias que ya está produciendo en las sociedades de los países desarrollados y que ahora quieren producir también en los países en vías de desarrollo, mediante la llamada 'salud reproductiva'." (Revoredo 1998: 593)

La tercera referencia es el libro del abogado argentino Jorge Scala (2010) - uno de los libros más difundidos en Brasil -, que recurre a Karl Marx, Jacques Derrida, Michel Foucault y Simone de Beauvoir, además de muchas otras teóricas feministas, para enseñar la base teórica del concepto de género. En el libro - traducido en Brasil en 2015 bajo el título Ideologia de Gênero: Neototalitarismo e a Morte da Familia - la alerta ante las amenazas del género está presente desde sus primeras páginas:

“La mal llamada 'teoría' - 'enfoque', 'mirada', etc.- de 'género' es, en realidad, una ideología. Probablemente la ideología más radical de la historia, puesto que - de imponerse -, destruiría al ser humano en su núcleo más íntimo y, simultáneamente acabaría con la sociedad. Además de ello, es la más sutil, porque no busca imponerse por la fuerza de las armas - como por ejemplo el marxismo y el nazismo -, sino utilizando la propaganda para cambiar las mentes y los corazones de los hombres, sin aparente derramamiento de sangre." (Scala 2010: 7)

Una de las más recientes referencias, ya muy conocida, es el libro del teólogo español José Manuel Guisasola, La Ideología de Género: Génesis Filosófica, Desarrollo Doctrinal e Incursión Jurídica (2018), que se centra en la búsqueda de las raíces de la "ideología de género". Sus conclusiones enfatizan las consecuencias de esa ideología, los obstáculos para su consumación y plantea propuestas para la resistencia cristiana. Recurriendo a un falso silogismo, el autor enumera seis de sus consecuencias: la dilución radical de las diferencias entre hombres y mujeres, la aceptación de todos los tipos de relaciones sexual, la eliminación del matrimonio heterosexual monógamo, la eliminación de la familia, la supresión de la maternidad biológica y la promoción del aborto. En cuanto a los obstáculos, menciona los límites morales, es decir, "el sistema ético occidental surgido del cristianismo", los límites legales, representados por "un corpus legislativo de protección y salvaguardia del matrimonio, de la familia y de la maternidad, construido por influencia de los valores religiosos" y el límite del cuerpo biológico (2018: 341-345). 
En su análisis, la ideología amenazadora es descrita como una afrenta contra la Iglesia Católica, por lo que le corresponde a ella impedir su avance: "La Iglesia Católica, como casi siempre, se vio sola en la lucha contra el avance de la ideología que pretende imponerse sin escrúpulos sobre las conciencias" (2018: 345). Finalmente, propone como formas de resistencia crear una oposición que luche en dos focos: el primero en las universidades, donde nació tal ideología, y el segundo en la sociedad, informándola de sus terribles consecuencias.

Según la genealogía propuesta por Miskolci y Campana (2017), las ideas difundidas por estos autores católicos estarían basadas, sobre todo, en los documentos del cardenal Joseph Aloisius Ratzinger y autor de la "pieza clave para comenzar a diseñar una contraofensiva político-discursiva poderosa contra el feminismo y su propuesta de reconocimiento y avance en materia de derechos sexuales y reproductivos" (Miskolci y Campana 2017: 726).

"Actualmente se considera a la mujer como un ser oprimido, así que la liberación de la mujer sirve de centro nuclear para cualquier actividad de liberación tanto política como antropológica, con el objetivo de liberar al ser humano de su biología. Se distingue entonces el fenómeno biológico de la sexualidad de sus formas históricas, a las que se denomina 'género', pero la pretendida revolución contra las formas históricas de la sexualidad culmina en una revolución contra los presupuestos biológicos. Ya no se admite que la 'naturaleza' tenga algo que decir. Es mejor que el hombre pueda moldearse a su gusto, tiene que liberarse de cualquier presupuesto de su ser: el ser humano tiene que hacerse a sí mismo, según lo cual, sólo de ese modo será 'libre' y liberado. Todo esto, en el fondo, disimula una insurrección del hombre contra los límites que lleva consigo como ser biológico. Se opone, en su extremo último, a ser criatura. El ser humano tiene que ser su propio creador, versión moderna de aquel 'seré como dios': tiene que ser como Dios." (Ratzinger 1997: 142)

Años más tarde, ya como papa Benedicto XVI, el sumo pontífice católico reafirmó sus opiniones sobre el género. En un mensaje navideño a la Curia Romana en 2008, declaró:

"Es necesario que haya algo como una ecología del hombre, entendida en el sentido justo. No es una metafísica superada, si la Iglesia habla de la naturaleza del ser humano como hombre y mujer y pide que se respete este orden de la creación. Aquí se trata del hecho de la fe en el Creador y de escuchar el lenguaje de la creación, cuyo desprecio sería una autodestrucción del hombre y, por lo tanto, una destrucción de la propia obra de Dios. Lo que con frecuencia es expreso y entendido con la palabra género, se resuelve, en definitiva, en la emancipación del hombre de la creación y del Creador. El hombre desea hacerse solo [...]. Pero, de esta manera, vive contra la verdad, vive contra el Espírito creador." (Papa Benedicto XVI 2008) 
El mensaje del sumo pontífice se sostenía en tres pilares: la reafirmación de la misión eclesiástica de salvaguardar las cosas divinas; el reconocimiento de la naturaleza, no sólo en su conjunto, sino y, sobre todo, del hombre concebido como don divino; así como la proposición de una "ecología del hombre" capaz de revertir su destrucción. Este extracto representa una formulación escatológica refinada de la tan divulgada ideología difundida por otros escritos.

El libro de Louis Sheldon (2012), Estratégia: O Plano dos Homossexuais para Transformar a Sociedade, se constituye como la principal referencia de la línea evangelista. El término "ideología de género", forjado en el linaje católico, no se emplea. No obstante, el término "género" aparece citado, en decenas de ocasiones, como parte de un argumento que interpreta la introducción de los conceptos de "género" e "identidad de género" como una "estrategia homosexual”, asimilada y publicada por los medios de comunicación de los Estados Unidos para influir en el contenido de políticas gubernamentales.

El libro reproduce las cuestiones observadas en los textos católicos, como la preocupación por contener el avance del género a través de políticas gubernamentales. El pánico moral también impregna su argumento. Sin embargo, el énfasis en sus manifestaciones no está en oponerse a un "contenido ideológico" cuya difusión se debe reprimir - como vimos en los documentos anteriores -, sino, principalmente, a personas específicas a las que se debe combatir:

"Los homosexuales que prohibieron las prácticas religiosas en todas las sociedades conocidas por el hombre y cuya esperanza de vida es la mitad de la de un heterosexual, contraen y propagan enfermedades contagiosas que han devastado naciones enteras, son sexualmente inmaduros, moralmente irresponsables y emocionalmente inestables. Son infieles a sus parejas $[\ldots]$, constantemente buscan aventuras eróticas, insultan a las minorías legítimas de los derechos civiles, y que difunden odio y violencia en nombre de la 'tolerancia' y de la 'diversidad'. Quieren que el gobierno federal 'incentive' y 'apoye' la enseñanza de su estilo de vida a los niños de los Estados Unidos. ¿A quién quieren engañar?” (Sheldon 2005: 147)

Otra publicación, muy mencionada en las redes sociales en Brasil, es el libro Ideologia de Gênero na Educação, de la psicóloga evangélica Mariza Lobo (2016). La autora afirma que, bajo el subterfugio de suscitar el respeto a la diversidad, la "ideología de género" ejerce la intolerancia y estimula el conflicto entre padres e hijos. Su reflexión dirigida al contexto escolar se detiene en explicar el establecimiento de una "dictadura de género" en las escuelas brasileñas y presenta medidas prácticas para combatirla. En sus argumentos resurge la preocupación por la infancia y la misma idea de que el género se disfraz de un discurso de respeto para promover la discriminación. 
El análisis bibliográfico y documental expuesto hasta ahora deja ver un conjunto de estrategias que se constituyó como una antítesis al género. Paradójicamente, reconocen la existencia de la perspectiva de género y sus avances, pero la entienden como una amenaza potencial a la sociedad y, como si de una sala de espejos se tratase, reproducen imágenes distorsionadas y provocan una serie de cambios semánticos estigmatizando el género bajo la categoría "ideología de género".

\section{Cambios semánticos y disputas alrededor del género}

El contenido de los libros y documentos descritos anteriormente - al igual que en los innumerables blogs, videos e imágenes divulgados agotadamente en las redes sociales - sugieren, al menos, tres cambios que me parecen rentables como caminos interpretativos, ya que permiten analizar algunos de los efectos de la enunciación de la "ideología de género" y cómo, en consecuencia, se fueron apropiando del concepto de "género" los grupos político-religiosos en Brasil y en otros países.

La primera transformación observada en estas publicaciones se refiere a la restauración discursiva de la indivisibilidad entre el sexo y género. Aquello que las teorías de género separaron, ahora los perseguidores de la "ideología de género" reunirán. Se hace evidente un esfuerzo de reiterar la relación unívoca y fija entre sexo y género. Por lo tanto, la naturaleza humana y heterosexual se compone inexorablemente de dos sexos - definidos por sus límites biológicos que se asocian, respectivamente, a roles femeninos y masculinos. Esta definición se opone a los enfoques feministas y de género, ya sea a aquellos que postularon el sistema sexo/género y la desnaturalización de las desigualdades entre hombres y mujeres (Rubin 1975), como a los que provocaron la desestabilización de las categorías sexo y mujer, antes concebidas como algo natural y fijo (Butler 1990). En este primer cambio, la reiteración de la "ideología de género" ratifica el binarismo sexual, rechaza las teorías de la desnaturalización y, al mismo tiempo, oculta todo lo que no se adecua a esa norma. Como sentencia Butler en su teoría de la performatividad: "lo que se 'actúa' sirve para ocultar, si no ya para renegar de aquello que permanece siendo opaco, inconsciente, irrepresentable" (Butler 2002: 329).

La segunda, por su parte, establece la separación entre mujer y género. La confusión entre mujer y género ha estado presente durante mucho tiempo en el pensamiento feminista, ya que el concepto de género se desarrolló en el marco de los estudios sobre la mujer (Piscitelli y Vasconcelos 2008). Esta confusión ha sido cuestionada por autoras como Joan Scott (1995), quien propuso el uso del género como una herramienta de análisis, rechazándolo como un sinónimo de estudios sobre mujeres. Su intento consistía en proponer un abordaje relacional según el cual, por ejemplo, no sería posible comprender la sumisión femenina sin considerar las masculinidades hegemónicas. 
No obstante, al separar mujer y género, esas discursividades, en verdad, rechazan el género propuesto por Scott y, por otra parte, niegan que la violencia contra las mujeres sea explicada por los procesos históricos y socioculturales de naturalización de las desigualdades basadas en el binarismo sexual. Este cambio es uno de los factores que hacen posible que algunos parlamentarios se declaren contra la violencia doméstica, sin reconocerla como una violencia basada en el género, sino como una amenaza a la familia heterosexual.

Finalmente, el tercer cambio expresa una relación sinonímica entre género y homosexualidad. Este nuevo sentido de género abarca la orientación sexual y, al mismo tiempo, recupera una expresión peyorativa rechazada hace mucho tiempo por los movimientos LGBT. Difunde el pánico moral convirtiéndose en un obstáculo, por ejemplo, para la discusión sobre la orientación sexual y la identidad de género en las escuelas. La constitución de un sujeto abyecto, los "homosexuales", enemigo de la infancia, de la familia y de la moral cristiana, que se puede analizar tanto en términos de Foucault (1988) mediante la biopolítica del control de las poblaciones, como desde Butler (2015) a través de las nociones de la abyección y la vulnerabilidad.

Estos tres cambios semánticos dan visibilidad a una disputa por el sentido del género generada por la difusión de la "ideología de género" y por su fricción con las teorías de género, los movimientos feministas y LGBT. Sin embargo, el análisis de esas publicaciones y la percepción de las disputas semánticas en torno al género me condujeron más allá, pues sus efectos exceden el ámbito de los conceptos y de los sentidos. De hecho, recurriendo al concepto de performatividad de Butler (2002, 2018), tal vez sea más apropiado hablar de performatividades religiosas, pues las discursividades productoras de la "ideología de género" estarían ellas mismas generando discursos autoritarios de género reiterados y legitimados por morales religiosas sostenidas en marcos jurídicos establecidos bajo su influencia.

Las performatividades religiosas - observadas a través de la actuación parlamentaria brasileña y de la producción bibliográfica cristiana - son producidas y legitimadas por normatividades autoritarias de género que operan: enunciando el género como una amenaza catastrófica, atribuyéndole cualidades despectivas, distorsionando sus sentidos originales, produciendo un sujeto particularmente abyecto y precarizado, y restableciendo relaciones y roles sociales más adecuados a la preeminencia biológica y a los cánones religiosos.

Analizando los actos enunciativos de la "ideología de género" bajo los términos de Butler (2002, 2018), es posible afirmar que el acto mismo de enunciación - reiterado en centenares de libros, proyectos de leyes, discursos parlamentarios, programas televisivos, videos en la web, etc. - hace posible su existencia. En otras palabras, el acto enunciativo confiere materialidad a esa categoría y cuando se produjo la apropiación por parte de segmentos como los parlamentarios evangélicos o líderes cristianos, originó efectos de poder como los descritos anteriormente. 
Como he tratado de demostrar, el parlamento brasileño se ha configurado como un escenario ejemplar para la confluencia estratégica entre las fuerzas católicas y evangélicas que lograron prohibir la "ideología de género" en la educación nacional. En los últimos años, esa alianza y sus efectos alcanzaron procesos políticos muy amplios que aún están promoviendo profundos cambios en la sociedad brasileña. En este contexto, y a través de un ecumenismo eficaz, las performatividades religiosas produjeron también una situación biopolítica de abyección, precariedad y muerte, o sea, "una situación políticamente inducida en la cual determinadas poblaciones sufren con las consecuencias de la deterioración de redes de apoyo sociales y económicas más que de otras, y quedan diferencialmente expuestas al daño, a la violencia y a la muerte" (Butler 2018: 40).

\section{LA EMERGENCIA DE LA “IDEOLOGÍA DE GÉNERO” EN EL LEGISLATIVO Y EXECUTIVO FEDERAL}

El cerco a la "ideología de género" encontró en el legislativo brasileño un campo privilegiado para su establecimiento y propagación, dejando al descubierto la confluencia estratégica de intereses entre grupos religiosos evangélicos y católicos. A través de un trabajo sistemático, perseverante y de gran alcance, esos parlamentarios cristianos, sumados a una amplia movilización popular, fueron capaces de eliminar la perspectiva de género de los principales marcos reguladores de la educación brasileña.

Para Fry y Carrara (2016) y Carrara (2015), la exclusión de los términos "género", "orientación y diversidad sexual" de los planes de educación ha representado otro round "en el proceso conflictivo de ciudadanización de diferentes sujetos sociales cuyas identidades se articulan ya sea en el lenguaje del género, o en el de la sexualidad u orientación sexual" (Carrara 2015: 324). En la misma perspectiva, Vianna e Lacerda (2004) y Natividade et al. (2009) sugieren comprender este escenario como un conjunto de batallas sucesivas para asegurar o contener el reconocimiento de los derechos sexuales y reproductivos en Brasil.

Sin embargo, las cuestiones de género y sexualidad en la educación ocuparon un lugar neurálgico en el debate sobre el PNE en 2014. Así emergió la "ideología de género" como un enemigo moral a perseguir. El debate del proyecto de ley que originó el PNE estuvo marcado por la movilización de grupos político-religiosos a favor de la exclusión de las expresiones "igualdad de género", "orientación y diversidad sexual" del texto de la ley, lo que provocó una intensa confrontación con los defensores de la perspectiva de género, sobre todo los movimientos feministas y LGBT.

En el documento oficial publicado tras la sanción de la ley, describe el choque sobre la cuestión de género como "la más ruidosa controversia" entre 
aquellas analizadas en el debate del proyecto de ley. La polémica se refería a "la superación de las desigualdades educativas" (inciso III, art. 2. ${ }^{\circ}$ ) y al énfasis en la promoción de la "igualdad racial, regional, de género y de orientación sexual" que, finalmente, fue sustituido por la "erradicación de todas las formas de discriminación" (Cunha 2016:10).

Este enfrentamiento fue más allá del legislativo federal y, años después, la cruzada legislativa contra la "ideología de género" - espectacularizada ejemplarmente durante la votación del PNE - llegó a las Cámaras de todos los estados brasileños, provocando nuevos conflictos en la aprobación de los planes regionales de educación. Dicha cruzada fue un éxito en la mayoría de los estados y municipios brasileños y los planes aprobados excluyeron expresiones relacionadas con el género y la sexualidad, y en pocos casos se sustituyeron por términos generales como "respeto a los derechos humanos" o "respeto a la diversidad".

En 2016, ya aprobados los planes de educación en todo el país, abundaron los proyectos para prohibir las discusiones sobre género y sexualidad en las escuelas, así como para la creación del programa Escuela sin Partido (ESP). Se repetían las censuras al "adoctrinamiento político o ideológico" y a la "ideología de género”, ambos definidos como prácticas y contenidos amenazadores para los niños, y perjudiciales para la autonomía de los padres a la hora de educar a sus hijos según sus principios morales.

$\mathrm{Si}$, en la superficie de la arena legislativa, la cruzada espectacular contra el género fue representativa al revelar la importancia y la centralidad del debate sobre derechos sexuales y reproductivos en el país, el análisis de ese proceso en los últimos cinco años me condujo hasta el trabajo legislativo ordinario y capilar de grupos político-religiosos, permitiéndome acceder al otro lado de la ofensiva legislativa. Esto destapó un prolongado y, al mismo tiempo, difuso esfuerzo de revocación de derechos tan recientemente conquistados, así como la negación de personas no heterosexuales por el lenguaje jurídico-legal.

En el año 2011, el mismo año en el que el Supremo Tribunal Federal reconoció la unión civil homoafectiva, sólo encontrábamos 16 proyectos de ley sobre el tema de los derechos sexuales y reproductivos. En 2012, el número de proposiciones llegó a 23, pero en 2015 las proposiciones legislativas llegaran a 125. En su mayoría expresaban el fortalecimiento de la ofensiva contra el género, aunque nos encontramos con otros que intentaban contenerla. ${ }^{3}$

En el área de la educación pública, los proyectos anhelaban restringir cualquier alusión a cuestiones de género y sexualidad en la enseñanza. Algunos de ellos, como el PL 10577/2018, sugirieron cambios en las directrices de la educación brasileña (Ley n. ${ }^{\circ}$ 9394/1996) “para prohibir la diseminación de la

3 Datos recogidos por Rafael Gomes y Thayná Boaes, presentados en el seminario "Violencia \& Género" (2016, Universidad Federal del Amazonas). 
ideología de género en las escuelas de Brasil" y otros propusieran la criminalización de prácticas concernientes a la efectividad de los derechos sexuales y reproductivos. ${ }^{4}$ Este es el caso del PL 3235/2015 del diputado Marco Feliciano (Partido Social Cristiano), ${ }^{5}$ el cual proponía ampliar el Estatuto da Criança e do Adolescente (Ley n. ${ }^{\circ}$ 8069/1990) e incluir la pena de prisión a cualquiera autoridad que divulgue "términos y expresiones como orientación sexual, identidad de género, discriminación de género, cuestiones de género y similares, así como autorizar la publicación de esas expresiones en documentos y materiales didáctico-pedagógicos".

En el área penal hubo intentos para reforma de la ley nacional contra la violencia doméstica y familiar contra las mujeres (Ley n. ${ }^{\circ}$ 1 1360/2006). Uno de estos intentos de reforma estaba dedicado a excluir la perspectiva de género, sustituyendo la palabra género por sexo. Hubo también peticiones que buscaban eliminar la obligatoriedad de información sobre orientación sexual e identidad de género en documentos policiales y notificaciones de salud, incluso en informes de mortalidad.

Como se ha podido observar, más que una expresión empleada de manera aleatoria y arbitraria, la "ideología de género" se constituyó como la pieza clave de un discurso religioso eficaz que encontró en el poder legislativo brasileño un lugar privilegiado para su establecimiento y propagación. Sus efectos más inmediatos han evidenciado cómo los grupos político-religiosos han sido capaces de excluir la perspectiva de género del lenguaje jurídico-legal y, con ello, perjudicar las políticas de reconocimiento.

Otros efectos se observaron en el 2018 por ocasión de las elecciones presidenciales:

"Nosotros necesitamos un presidente honesto, que tenga a Dios en el corazón, sea patriota y sea independiente para con su ejemplo gobernar a este gran país. Un presidente que honre y respete la familia, que trate con consideración al niño, no admitiendo la ideología de género e imponiendo la Escuela sin Partido. Un presidente que no divida homos y heteros, padres e hijos, nordestinos y sureños, blancos y negros, ricos y pobres. Un presidente que deje atrás el comunismo y el socialismo."6

Tras la primera vuelta de las elecciones, en entrevistas a las emisoras brasileñas de televisión, el candidato elegido para la presidencia de Brasil (2019-2022) reiteró tanto su objeción a la “ideología de género" como su compromiso

4 Disponible en < https://www.camara.leg.br/proposicoesWeb/fichadetramitacao?idProposicao $=218$ $1575>$ (última consultación en octubre 2021).

5 Disponible en < https://www.camara.leg.br/proposicoesWeb/fichadetramitacao?idProposicao $=201$ $6875>$ (última consultación en octubre 2021 ).

6 Disponible en < https://youtu.be/qxrcwruYLps > (última consultación en octubre 2021). 
con la imposición del programa ESP. ${ }^{7} \mathrm{Al}$ referirse al respeto a la familia y a los niños, al tiempo que rechazaba el comunismo y el socialismo, reafirmó su oposición al "adoctrinamiento" y a la "sexualización infantil". 8

Al mencionar el respeto por la familia y los niños, mientras rechaza la ideología de género, el comunismo y el socialismo, el candidato reafirmó su oposición a lo que llamó, en su propuesta de gobierno, "adoctrinamiento y sexualización precoz". Entre las sugerencias para la educación nacional, su plan aún mencionó la intención de cambiar la Base Curricular Nacional Común (BCNC) ${ }^{9}$ y de "depurar" la "ideología de Paulo Freire" ${ }^{10}$ de la educación brasileña. ${ }^{11}$

El contenido de su declaración y plan de gobierno es revelador, ya que, por un lado, representa el modo en que los grupos político-religiosos lograron difundir en Brasil la oposición a la "ideología de género", hasta el punto de formar parte de los programas electorales junto a asuntos como seguridad pública y corrupción y, por otro lado, evidencia cómo grupos anti-izquierda diseminaron, con igual éxito, la expresión "adoctrinamiento ideológico" como herramienta para la criminalización docente y judicialización (Rifiotis 2014) de las relaciones escolares.

No por casualidad, su mención a la "ideología de género" y al "adoctrinamiento ideológico", remite a la misma aproximación discursiva observada en publicaciones cristianas internacionales y a propuestas legislativas para la reforma de la educación en Brasil. El extracto expone, además, los efectos de una poderosa alianza entre grupos político-religiosos, representados mayoritariamente por el Frente Parlamentario Evangélico del Congreso Nacional, ${ }^{12}$ así

7 Creado en 2004 por el movimiento homónimo, proponía cambios en la Ley de Directrices y Bases de la Educación para garantizar el "respeto a las convicciones y a los valores morales y religiosos de estudiantes y de sus familias" y la prohibición de la "ideología de género". En noviembre de 2018 la propuesta fue archivada. Sin embargo, dos nuevos proyectos de ley (PL 246/2019 y PL 258/2019) fueron presentados en 2019.

8 Consultado en < https://youtu.be/qxrcwruYLps > (última consultación en diciembre 2018, ya no disponible).

9 Documento que estandariza el aprendizaje y el currículo de la educación básica en Brasil. Luego de un amplio y conflictivo proceso iniciado en 2015, en diciembre de 2017 se aprobó el texto de la base de educación infantil y educación primaria. Disponible en < http://basenacionalcomum.mec.gov.br/ > (última consultación en octubre 2021).

10 Paulo Freire (1921-1997) fue un pedagogo y filósofo brasileño de notable influencia para la pedagogía crítica mundial. En el libro Pedagogia do Oprimido (1968), una de sus obras más populares, propuso una nueva relación enseñanza-aprendizaje basada en un proceso de valoración a priori del conocimiento y el compromiso con la emancipación y liberación de los oprimidos.

11 Consultado en < http://www.psl-sp.org.br/ > (última consultación en diciembre 2018, ya no disponible).

12 La "bancada evangélica" se formó en 2005 y se consolidó con el ingreso del diputado y pastor Marcos Feliciano (Partido Social Cristiano - PSC) en la Comisión de Derechos Humanos (2013) y la asunción del diputado Eduardo Cunha (Movimiento Demócrata Brasileño - MDB) a la presidencia de la Cámara (2015). En el mismo año fue registrada como Frente Parlamentario Evangélico. Disponible en < https://www.camara.leg.br/ > (última consultación en octubre 2021). 
como por grupos de liberales y de extrema derecha como el Movimiento Brasil Libre (MBL), ${ }^{13}$ el Revoltados On-Line ${ }^{14}$ y el ESP.

Esta alianza no se forjó en la última campaña presidencial, sino que es el resultado de procesos que, en Brasil, están en marcha desde hace al menos una década. Este es el caso del ESP, cuya principal oposición se dirigió al supuesto contenido comunista (o de izquierda) observado en la educación pública brasileña. Sin embargo, la gran proyección del ESP ocurre precisamente cuando sus propuestas son incorporadas por otro aspecto de la agenda conservadora: el combate a la llamada "ideología de género" (Miguel 2016: 595), combinando dos frentes del conservadurismo contemporáneo en Brasil: el anticomunismo y el fundamentalismo religioso cristiano.

\section{Estrategias discursivas y el género como catástrofe}

En los contenidos analizados, algunas estrategias aparecen con más fuerza y regularidad. Una de ellas es la amenaza a la niñez, manifiesta en prácticamente todas las fuentes investigadas. Evocar la infancia, su fragilidad y la necesidad de protección es una importante herramienta para reivindicar una educación moral basada en los valores religiosos y en la autoridad familiar. La expresión "totalitarismo de Estado" es forjada en este sentido por Scala (2010) para impugnar la intervención del Estado que, en una supuesta acción autoritaria e irrespetuosa impone el género, interfiere en la educación de los niños y hiere la libertad de los padres de educar a sus hijos según sus valores morales. Se trata pues de la misma trampa liberal criticada por Butler en Quadros de Guerra (2015).

La denuncia de una conspiración internacional entre marxistas, comunistas, feministas y movimientos LGBT es otro importante componente discursivo, además de lo más agregador, pues ha permitido que grupos no religiosos se sumen al ataque al "género", como se percibe entre los defensores del ESP. Según Miguel (2016), esta confluencia es el resultado de una estrategia exitosa del movimiento ESP, ya que cuando surgió en 2004, su idea principal se centraba en combatir la doctrina marxista, un temor difundido desde los años de dictadura militar. Al añadir a su pauta original la cuestión de género, "transfirió la discusión a un terreno aparentemente 'moral' y pasó a enmarcarla en términos de una disputa entre escolarización y autoridad de la familia sobre los niños" (Miguel 2016: 595-596), lo que reitera la primera estrategia. Aunque el término "ideología de género" y su difusión tengan origen en una ofensiva

13 Creado en 2014 y autodefinido como un movimiento en defensa del liberalismo económico. Disponible en < http://www.psl-sp.org.br/ > (última consultación en octubre 2021).

14 Surgió en 2000 para denunciar pedófilos en las redes sociales. En 2010 empezó su actuación contra la corrupción y, después, en favor del impeachment. Disponible en < https:/www.vakinha.com.br/ vaquinha/ajude-revoltados-on-line-marcello-reis > (última consultación en octubre 2021). 
cristiana, otros grupos se apropiaron del término y actúan con igual fuerza en ese campo de disputa (Biroli 2019).

Otra de las estrategias es la del sexo como categoría normativa, lo que una vez más nos remite al pensamiento de Butler (2002). Los intentos por sustituir en los textos legales las palabras "género" o "diversidad sexual" por "sexo", además de la reiteración de un límite biológico binario, demuestran la imposición del sexo como norma y práctica reguladora. Sus efectos de poder producen los cuerpos que gobiernan y, así, demárcalos y diferéncialos (Butler 2002: 17-18). Ese proceso de materialización de las normas tiene una estrecha relación con la abyección y precarización, pues el acto de enunciar, delimitar y diferenciar es también excluyente. Otro aspecto relevante de esta estrategia es como el sexo binario - del que se deriva la heterosexualidad y la familia monógama - es lo que garantiza la continuidad de la sociedad, dictada como la reproducción biológica de la especie humana.

Otra estrategia observada en los libros analizados, particularmente intrigante, es la ausencia de reiteración de la antigua oposición: ciencia vs. religión - aunque restablezcan el antagonismo Iglesia vs. Universidad -, mientras encontramos la reivindicación de una ciencia verdadera. Efectivamente, cuestionan la cientificidad del género y enfatizan su carácter ideológico, es decir, su poder de falsear la realidad. Al mismo tiempo, recuren a la biología para sostener la existencia de una naturaleza creada por Dios y vulnerada por la acción humana. Por lo tanto, reconocer la biología hace parte del esfuerzo reiterativo de la materialidad del sexo. En el discurso del papa Benedicto XVI, la ciencia es ejemplarmente reivindicada a través de la ecología.

Por otro lado, esta estrategia reitera la oposición ciencia vs. política. Por ser ideológico y, por lo tanto, político, el género no sería científico. Aquí se encuentra otra trampa, la que niega el carácter político de la ciencia reforzando su separación de la política. Aunque exista en el campo científico quien defienda tal separación, como argumentó Latour (2014: 19), "no hay conflicto entre ciencia y política, pero hay un conflicto entre dos epistemologías políticas radicalmente opuestas, cada una con su propia definición de lo que viene a ser ciencia y política, y de cómo ambas podrían colaborar una con otra".

Aunque los principales documentos indiquen la influencia de países más desarrollados o el dominio norteamericano, la quinta estrategia, contrariamente, consiste en imponer un proyecto colonial y autoritario que reivindica el restablecimiento de los términos jurídicos forjados según la perspectiva cristiana y occidental, como bien explica Guisasola (2018). Esa táctica me parece muy evidenciada en el esfuerzo legislativo de negar el reconocimiento de personas no heterosexuales en el lenguaje jurídico-legal.

Finalmente, la principal estrategia concierne al carácter profundamente escatológico de la "ideología de género" que se configura como una poderosa fabulación sobre el fin del mundo. Al igual que en otras narrativas de no-futuro, 
este nuevo mito anuncia una catástrofe de proporciones alarmantes provocada por la propagación de una nefasta teoría pseudocientífica que rechaza la naturaleza humana y promueve - como en el idílico Brave New World (Huxley 2018 [1939]) - la extinción de la maternidad y la reproducción artificial de seres sexualmente indeterminados. Según la narrativa mítica, esta ideología, disfrazada de políticas de respecto a la diversidad o de protección a las mujeres, fue legitimada por políticas totalitarias de Estado inducidas por la ONU y que destituyen la autoridad familiar. Hacen de los niños sus principales víctimas y señalan que la insensatez de activistas sexuales, feministas, homosexuales y comunistas nos conducirá a la destrucción de la familia y del hombre.

El fin del mundo, como sabemos, es objeto inagotable de especulación en el cine, la literatura, la ciencia y la teología. El mensaje papal de Benedicto XVI es una sofisticada formulación en la cual el género es prefigurado como un acontecimiento catastrófico capaz de promover la extinción humana. No se trata, pues, cómo afirmó el mismo pontífice, de una serie de afirmaciones, no sólo metafísicas, sino también de la resignificación del discurso científico de la ecología, una ciencia que nutre especialmente la preocupación por el fin del mundo y del ser humano como consecuencia de su relación predatoria con la naturaleza.

Esta dimensión apocalíptica agrega afectos importantes para nuestro estudio y recupera aspectos centrales de la fe cristiana como la punición, la culpa y la muerte, pero también el arrepentimiento, la conversión y la vida eterna. En términos bíblicos, el mundo finito es el mundo de quien desafía la voluntad divina, de quien no vive según las normas cristianas y esos "sufrirán pena de eterna perdición, excluidos de la presencia del Señor y de la gloria de su poder" (2 Tesalonicenses 1:9). Sin embargo, aquellos que rechazan el pecado vivirán, pues "el que hace la voluntad de Dios permanece para siempre" (1 Juan 2:17). Al revelar la "trampa" del género, se profetiza el fin del mundo destrozado por el pecado (la promiscuidad, la reproducción artificial, la perversión de la niñez) y de los pecadores (homosexuales, activistas sexuales, feministas, comunistas) que sucumbirán en el juicio final. No obstante, la revelación es al mismo tiempo una acusación, una advertencia, un juicio y una invitación: aún hay tiempo para cambiar las mentes y los corazones, conocer la verdad y liberarse.

Además del conflicto epistemológico, esta estrategia revela la existencia de mundos distintos en conflicto, lo que requiere comprender la lógica y los fundamentos de esta estrategia apocalíptica en el seno del pensamiento cristiano. Así, tal vez, seamos capaces de comprender la potencia y las amenazas de esas performatividades.

\section{CONCLUSIONES}

En ese artículo, he intentado describir aspectos constitutivos del contexto de emergencia de la cruzada contra la "ideología de género" en Brasil. Aunque este 
sea un fenómeno transnacional, opté por concentrarme en los efectos de difusión de esa categoría a través de algunos acontecimientos emblemáticos de la historia reciente brasileña: la exclusión de la perspectiva de género del PNE, la destitución de la presidenta Dilma Rousseff y el fortalecimiento de la extrema derecha.

Para analizar las discursividades productoras de esa categoría, tuve en cuenta algunas de las principales referencias cristianas, a través de las cuales he tratado de llevar a cabo un mapeo de los principales autores, libros y argumentos que sostienen la "ideología de género", lo que me ha permitido trazar una génesis de su proceso formativo. El análisis del material bibliográfico y documental ha permitido evidenciar un conjunto de cambios semánticos producidos por performatividades religiosas, cuyos efectos de poder generan abyección, precariedad y muerte.

Estos efectos han podido ser expuestos, de forma más evidente, en la descripción del proceso de aprobación del PNE y la subsiguiente avalancha legislativa en la que se observó una coalición cristiana para la revocación de leyes, la negación de derechos a mujeres y personas LGBT y la producción de la invisibilidad de personas no heterosexuales. Una actuación, por lo demás, muy coherente con el análisis recientemente publicado por Almeida (2019: 210): "el conservadurismo religioso oscila entre resistir a los cambios, provocar cambios regresivos y adherirse a ciertos valores de este mundo".

Finalmente, importa decir que, además de los hechos antes descritos y analizados, circunscritos al territorio y procesos políticos brasileños, existe una colección de acontecimientos ocurridos en otras partes del mundo que evidencian la transnacionalización del proceso descrito en estas líneas. El Acuerdo de Paz en Colombia (2016), las elecciones presidenciales en Brasil (2018) y la emergencia del Partido Vox en España (2019) demuestran que los efectos de la propagación de esa categoría superan el campo de los derechos sexuales y reproductivos y los límites nacionales. Es evidente, pues, que tales performatividades religiosas producen prácticas articuladas y muy exitosas, gracias a las cueles han logrado interferir en procesos de gran alcance en la vida política de los países en los cuales están insertados.

Todavía faltan por cumplir algunas tareas: la primera sería añadir a este análisis una perspectiva más etnográfica para conocer mejor la profundidad y la extensión de sus efectos en la vida ordinaria. La segunda es comprender las relaciones y los intereses aportados por cada uno de los grupos religiosos y seculares que hacen parte de la persecución transnacional contra el género. Por último, quizá, un estudio geopolítico transnacional en que sea posible conocer los marcos más generales de esos fenómenos. Este esfuerzo puede ayudarnos en la producción de otros caminos de alianza, solidaridad y resistencia. ${ }^{15}$

15 Esta publicación tuvo el apoyo de la Universidade Federal do Amazonas y de la Coordenação de Aperfeiçoamento de Pessoal de Nível Superior 


\section{BIBLIOGRAFÍA}

ALMEIDA, Ronaldo de, 2019, "Bolsonaro presidente: conservadorismo, evangelismo e a crise brasileira”, Novos Estudos Cebrap, 38 (1): 185-213.

BALIEIRO, Fernando de Figueiredo, 2018, "Não se meta com meus filhos: a construção do pânico moral da criança sob ameaça", Cadernos Pagu, 53: el85306.

BIROLI, Flavia, 2019, "O recesso da democracia e as disputas em torno da agenda de gênero”, Boletim Lua Nova. Consultado en < https://boletimluanova.org/2019/05/13/ > (última consultación en mayo 2019, ya no disponible).

BORGES, Rafaela Oliveira, y Zulmira Newlands BORGES, 2018, "Pânico moral e ideologia de gênero articulados na supressão de diretrizes sobre questões de gênero e sexualidade nas escolas", Revista Brasileira de Educação, 23: e230039.

BUTLER, Judith, 1990, Problemas de Gênero: Feminismo e Subversão da Identidade. Rio de Janeiro: Civilização Brasileira.

BUTLER, Judith, 2002, Cuerpos que Importan: Sobre los Limites Materiales y Discursivos del "Sexo". Buenos Aires: Paidós.

BUTLER, Judith, 2015, Quadros de Guerra: Quando a Vida É Passível de Luto. Rio de Janeiro: Civilização Brasileira.

BUTLER, Judith, 2018, Corpos em Aliança e a Politica das Ruas: Notas para Uma Teoria Performativa de Assembleia. Rio de Janeiro: Civilização Brasileira.

CARRARA, Sérgio, 2015, "Moralidades, racionalidades e políticas sexuais no Brasil contemporâneo”, Mana, 21 (2): 323-345.

CORNEJO-VALLE, Mónica, y José Ignacio PICHARDO, 2017, “La ‘ideología de género’ frente a los derechos sexuales y reproductivos en el escenario español”, Cadernos Pagu, 50: el75009.

CORRÊA, Sonia, 2018, “A 'política do gênero’: um comentário genealógico”, Cadernos Pagu, 53: el85301.

CUNHA, Flávia Melo da, 2016, "O túnel, o Frota, a ideologia de gênero", Ponto Urbe, 18: 1-14. Disponible en < https://doi.org/10.4000/pontourbe.3137> (última consultación en octubre 2021).

FOUCAUlT, Michel, 1988, História da Sexualidade I: A Vontade de Saber. Rio de Janeiro: Graal.

FRANCISCO, Adilson José, 2011, "Pare de sofrer: trânsitos religiosos e televangelismo na fronteira", Horizonte, 9 (22): 446-465.

FRY, Peter, y Sergio CARRARA, 2016, "Se oriente, rapaz! Onde ficam os antropólogos em relação a pastores, geneticistas e tantos 'outros' na controvérsia sobre as causas da homossexualidade?”, Revista de Antropologia, 59 (1): 258-280.

GARBAGNOLI, Sara, 2014, "Lideologia del genere: l'irresistibile ascesa di un'invenzione retorica vaticana contro la denaturalizzazione dell'ordine sessuale", About Gender Rivista Internazionale di Studi di Genere, 3 (6): 250-263.

GUISASOlA, José Manuel Martínez, 2018, La Ideología de Género: Génesis Filosófica, Desarrollo Doctrinal e Incursión Jurídica. Sevilla: Punto Rojo Libros.

HUXLEY, Aldous, 2018 [1939], Un Mundo Feliz. Madrid: Debolsillo.

JUNQUEIRA, Rogerio Diniz, 2017, "Ideologia de gênero: a gênese de uma categoria política reacionária ou a promoção dos direitos humanos se tornou uma ameaça à família natural?", in Paula Regina Costa Ribeiro y Joana Lira Magalhães, Debates Contemporâneos sobre Educação para a Sexualidade. Rio Grande: Edições FURG. 
LATOUR, Bruno, 2014, "Para distinguir amigos e inimigos no tempo do Antropoceno", Revista de Antropologia, 57 (1): 11-31. Disponible en < https://doi.org/10.1 1606/2179-08 92.ra.2014.87702 > (última consultación en octubre 2021).

LOBO, Marisa, 2016, A Ideologia de Gênero na Educação. S. 1.: Mariza Lobo Ministério.

LÓPEZ, Jairo Antonio, 2018, "Movilización y contramovilización frente a los derechos LGBTI: respuestas conservadoras al reconocimiento de los derechos humanos", Estudios Sociológicos, 36 (106): 161-187.

LUNA, Naara, 2017, “A criminalização da 'ideologia de gênero’: uma análise do debate sobre diversidade sexual na Câmara dos Deputados em 2015”, Cadernos Pagu, 50: el 75018.

MIGUEL, Luis Felipe, 2016, “Da 'doutrinação marxista' à 'ideologia de gênero': escola sem partido e as leis da mordaça no parlamento brasileiro”, Direito \& Práxis, 7 (15): 590-62 1.

MISKOLCI, Richard, y Maximiliano CAMPANA, 2017, "Ideologia de gênero: notas para a genealogia de um pânico moral contemporâneo", Sociedade e Estado, 32 (3): 725-748.

NATIVIDADE, Marcelo, Luís Fernando Dias DUARTE, Edlaine de Campos GOMES, y Rachel Aisengart MENEZES, 2009, Valores Religiosos e Legislação no Brasil: A Tramitação de Projetos de Lei sobre Temas Morais Controversos. Rio de Janeiro: Garamond/FAPERJ.

O'LEARY, Dale, 1997, The Gender Agenda. Laffayette: Vital Issues Press.

PAPA BENEDICTO XVI, 2008, "Discurso do Papa Bento XVI à Cúria Romana por ocasião dos votos de Feliz Natal". Disponible en < http://www.vatican.va/content/benedict-xvi/pt/ speeches/2008/december/documents/hf_ben-xvi_spe_20081222_curia-romana.html > (última consultación en octubre 2021).

PATERNOTTE, David, y Roman KUHAR, 2018, "Disentangling and locating the 'global right': anti-gender campaigns in Europe”, Politics and Governance, 6 (3): 6-19.

PISCITELli, Adriana, y Marcia VASCONCELOS, 2008, "Apresentação", Cadernos Pagu, 31 : 9-28.

PRANDI, Reginaldo, y João Luiz CARNEIRO, 2018, “Em nome do pai: justificativas do voto dos deputados federais evangélicos e não evangélicos na abertura do impeachment de Dilma Rousseff", Revista Brasileira de Ciências Sociais, 33 (96): e339603.

RATZINGER, Joseph A., 1997, La Sal de la Tierra. Madrid: Libros Palabra.

REVOREDO, Oscar Alzamora, 1998, “Ideología de género: sus peligros y alcances”. Disponible en < https://www.aciprensa.com/controversias/genero.htm > (última consultación en octubre 2021).

REVOredo, Oscar Alzamora, 2004 [1998], La Ideología de Género: Sus Peligros y Alcances. Lexicón de Términos Ambiguos y Discutidos sobre Familia, Vida y Cuestiones Éticas. Madrid: Palabra.

RIFIOTIS, Theophilos, 2014, "A judicialização e as configurações do sujeito 'conflito com a lei’: reflexões sobre um sujeito compósito”, IV Seminário Internacional Violência e Conflitos Sociais: Territorialidades e Negociações. Disponible en < https://www.researchgate.net/public ation/270899733_A_judicializacao_e_as_configuracoes_do_sujeito_conflito_com_a_ lei_reflexoes_sobre_um_sujeito_composito > (última consultación en octubre 2021).

RONDÓN, Manuel Alejandro R., 2017, "La ideología de género como exceso: pánico moral y decisión ética en la política colombiana”, Sexualidad, Salud \& Sociedad, 27: 128-148.

RUBIN, Gayle, 1975, “The traffic in women: notes on the 'political economy' of sex", in Rayna Reiter, Toward an Anthropology of Women. Nueva York: Monthly Review Press.

RUBIN, Gayle, 1993, "Thinking sex: notes for a radical theory of the politics of sexuality", in Henry Abelove, Michele Barale y David Halperin, The Lesbian and Gay Studies Reader. Nueva York: Routledge. 
SCALA, Jorge, 2010, La Ideología del Género o el Género como Herramienta de Poder. Rosario/ Argentina: Ediciones Logos.

SCOTT, Joan W., 1995, "Gênero: uma categoria útil de análise histórica”, Educação \& Realidade, 20 (2): $71-99$.

SHELDON, Louis, 2012, Estratégia: O Plano dos Homossexuais para Transformar a Sociedade. Rio de Janeiro: Central Gospel.

STOLLER, Robert, 1964, "A contribution to the study of gender identity", The International Journal of Psychoanalysis, 45: 220-226.

VAGGIONE, Juan Marco, 2010, El Activismo Religioso Conservador en Latinoamérica. Córdoba: Católicas por el Derecho a Decidir/Hivos.

VIANNA, Adriana, y Paula LACERDA (orgs.), 2004, Direitos e Políticas Sexuais no Brasil: O Panorama Atual. Rio de Janeiro: CLAM/IMS/UERJ.

VIGOYA, Mara Viveros, y Manuel Alejandro Rodríguez RONDÓN, 2017, "Hacer y deshacer la ideología de género", Sexualidad, Salud \& Sociedad, 27: 118-127.

Receção da versão original / Original version Aceitação / Accepted

Pré-publicação online / Pre-published online
$2019 / 08 / 06$

$2020 / 07 / 09$

$2021 / 05 / 18$ 